\title{
NEGATIVE PHENOMENA IN THE FAMILIES OF MODERN UKRAINE
}

УДК 316.22: 331.108 (447)

DOI https://doi.org/10.32843/26635208.2020.11.8

\section{Малахова ж.д.}

к.и.н., профессор,

академик Академии наук СТ и МС, профессор кафредры социальной работы

Мелитопольский институт экологии и социальных технологий

Открытого международного

университета развития человека «Украина»

\begin{abstract}
Криза суспільства України позначилась на сім'ї і сімейно-шлюбних відносинах в українських сім'ях, які загострилися останнім часом. У статті особливу увагу приділено таким явищам, як насильство в сімїі; статеві збочення (сексуальні домагання, сексуальний примус, сексуальна експлуатація дітей і підлітків), співжиття, погане виховання дітей в сімї; наявність у суспільстві «дітей вулиці» і осіб без певного місия проживання (бомжів), поширення ВІЛ та СНІДу. у родині діє складна система взаємовідносин, де кожен член родини виконує свою соціальну роль. Неякісне виконання своєі соціальної ролі $\epsilon$ негативним моментом та частіше всього приводить насамперед до виникнення різних сімейних конфрліктів, до непорозуміння партнерів та закінчується розпадом сімейно-шлюбних відносин.

у статті розглядається:1) насильство в сім'ї, як між партнерами, так і щодо дітей; 2) негативні явища співжиття; 3) гомосексуалізм та лесбіянство, зокрема, дана оцінка українців одностатевим сім'ям.

Ключові слова: суспільство, сім'я, сімейно-шлюбні відносини, насильство в сім'ї, сексуальні збочення, співжиття, сімейне виховання дітей, ВІЛ та СНІД.
\end{abstract}

The crisis of society in Ukraine affected the family and family-marital relations in Ukrainian families, which have intensified recently. The article focuses on such phenomena. The crisis of society in Ukraine affected the family and fam- ily-marital relations in Ukrainian families, which have intensified recently. The article focuses on such phenomena as domestic violence; sexual perversions: sexual harassment, sexual coercion, sexual exploitation of children and adolescents; cohabitation; poor parenting in the family; the presence in the society of "children from the street" and people without a fixed place of residence (homeless people); the spread of HIV and AIDS.

The family has a complex system of relationships, where each of members of the family fulfills its social role. Violation in the performance of one's social role is an unfavorable moment and often leads first to the emergence of various family conflicts, and then to a misunderstanding of partners and ends with the collapse of family and marriage relations.

The article discusses: 1) domestic violence both from partners to each other, and violence, sexual perversions in relation to children; 2) negative traits of cohabitation; 3) homosexuality and lesbianism, and given the assessment of Ukrainians to equal families; 4) the problems of raising children and the participation of parents in the educational process.

The article discusses violations of social roles in the family, as well as the attitude of Ukrainians towards common European values, such as cohabitation, same-sex marriage: homosexuality and lesbianism.

Key words: society, family, family-marital relations, domestic violence, sexual perversions, cohabitation, same-sex marriage, family education of children, HIV, AIDS.
Постановка проблемы. В развитии личности особо важное место занимает семья, та атмосфера, которая царит в ней, включающая взаимоотношения родителей, отношения к детям, взаимопонимание взрослых и подрастающего поколения. Социологические исследования показывают, что дети чаще всего при создании своих собственных семей повторяют стереотипы поведения, которые были свойственны их родителям вместе с теми же недостатками, наблюдаемые ими в детстве. Недаром говорят, что «все мы из детства». Вот почему негативные отношения в семье оказывают губительное воздействие на становление личности в целом, а также на ту культуру построения современной семьи, которая закладывается в личности в самые ранние годы её развития. Негативные явления в семье калечат души детей, отрицательно сказываются на их воспитании, разрушают устои самой семьи.

В статье рассматриваются негативные явления, которые особенно заострились в период кризиса семьи.
Анализ последних исследований и публикаций. В Украине проблемы семьи и брака изучали Л.А. Аза, Л.М. Бучинская, С.М. Вакуленко, Н.В. Лавриненко, С.М. Оксамитна, В.М. Пича, В.Ф. Рыбаченко, О.Д. Цымбалюк, Ю.М. Якубова и др. [12, с. 29]. Они изучали демографические проблемы семьи, репродуктивное поведение партнёров, объединение профессиональных и семейных ролей, распределение обязанностей в семье и другие важные вопросы, касающиеся семейной жизни.

За последние годы появились публикации и социологические исследования о негативных явлениях в семье: нарушении социальных ролей в семейно-брачных отношениях, насилии в семье, сексуальных извращениях, проблемах воспитания детей в условиях полной занятости родителей вне дома, среди которых наиболее известными являются работы А.В. Лысовой «О границах радикальной феминистской теории и объяснение насилия в семье»; Н. Гоцуенко «Такая супружеская пара: муж - неженатый, жена - замужем»; В. Кожевниковой «Місце сімейного права 
в системі правового права України»; Соцопрос vox populi «Четверть украинских подростков пробовали наркотики»; Т. Хлебниковой «Ни лечиться, ни работать»; В.В. Щербины «Норми та девіації сучасного шлюбу» [4; 6; 14].

Постановка задания. Цель статьи - показать на примерах социологических исследований проблемы семей современной Украины, так как, по мнению автора статьи, последние публикации об украинских семьях не дают общей картины изменений, происшедших за период провозглашения независимости Украины. Надеюсь, что данная статья ликвидирует этот пробел.

Изложение основного материала исследования. Семья - один из элементов микросреды, в которой формируется личность человека. В семье действует сложная система взаимоотношений, где каждый её член выполняет свою социальную роль. Нарушение в исполнении своей социальной роли является неблагоприятным моментом и зачастую приводит сначала к возникновению различных семейных конфликтов, а потом к недопониманию партнёров и заканчивается распадом семейно-брачных отношений.

Так, например, нарушение традиционного принципа, что муж является главой семьи, её хранителем, защитником, основным источником материального благополучия семьи, так называемым добытчиком, приводит чаще всего к возрастанию роли женщины (жены), которая зарабатывает больше супруга и не хочет мириться с тем, что муж перестал быть главою семьи. В особенности это касается семей, где муж потерял работу, длительное время не может трудоустроиться и становится не добытчиком, а скорее потребителем, пассивным членом семьи. Утрата главенствующей роли мужа в семье становится причиной потери авторитета мужчины в доме не только со стороны жены, но и со стороны других членов семьи: детей, родителей, ближайших родственников. К сожалению, за годы независимости Украины, когда закрылись многие промышленные предприятия и резко возросла безработица, а перейти к другим видам деятельности многие мужчины оказались неспособными, выросло число разводов, а также увеличилась численность суицида среди мужчин наиболее продуктивного возраста от 40 до 55 лет.

Утрата авторитета родителей пагубно отражается на взаимодействии родителей детей, так как последние не видят в родителях примера для подражания, порождают у подростков вседозволенность, которая приводит к праздному образу жизни, потреблению наркотиков, потере социальных ориентиров.

Нельзя обойти молчанием и такое негативное явление, как насилие в семье.
Семейное насилие - физическое извращение, применяемое одним членом семьи по отношению к другому или к остальным членам семьи $[4$, с. 142$]$.

Насилие в семье - это не гендерная проблема, это социальная, человеческая проблема. Она объясняется рядом факторов, среди которых, во-первых, семья основана на эмоциональных, духовных связях её членов, причём нередко чувства любви сопровождается чувством ненависти, а во-вторых, семейные конфликты между супругами часто разрешаются драками. Данные статистики свидетельствуют о том, что дома человек чаще является предметом насилия, чем ночью на улице. Одно из четырёх убийств в Великобритании совершается в семье. Такая же статистика наблюдается и в Украине, и в других странах СНГ.

Социологические исследования показывают, что обычно насилие применяется к детям или со стороны мужа по отношению к жене. Избиение жены феминистские теоретики объясняют не только большей физической силой у большинства мужчин по отношению к женщине, но и культурным климатом общества в целом, поддерживающим «мужское господство» $[1$, с. 231].

Феминизм (фр. feminisme < лат. femina женщина) - общее название течений в женском движении по уравнению в правах женщин с мужчинами [11, с. 523].

Феминизм имеет долгую историю, начиная c XV столетия. Корни современной феминистской мысли прослеживаются с конца XVIII столетия. Активизация феминизма сопровождается периодами относительного затишья. Выделяют по активизации феминизма «первую волну» (середина XIX - начало XX столетия) и «Вторую волну» (конец 1960-х гг. по настоящее время). Сибистайн (1978) выявила свыше десятка политических тенденций внутри феминизма в диапазоне от либеральной позиции равноправия до требований женского верховенства. Палмер (1989) выявила следующие тенденции феминизма: академический, культурный, лесбийский, либеральный, психоаналитический, радикальный, социалистический, а также политическое лесбиянство. В настоящее время экологический феминизм особенно развивается внутри радикального феминизма [1, Т.2, с. 385-387].

Из многих современных направлений внутри феминизма наиболее существенными из них являются радикальный и либеральный феминизм. С позиции радикального феминизма женщина видится в основном в роли жертвы насилия, а мужчина - в роли агрессора. Поэтому радикальный феминизм заявляет о проблеме «насилия против женщин», а не «насилия в семье». Даже когда женщина 
убивает мужа или партнёра, женщина часто представляется жертвой, а её поведение смягчается, потому что радикальный феминизм ввёл понятие «синдром избиваемой жены». Некоторые женщины в США избежали наказания, уголовной ответственности за убийства или травмы, нанесенные ими своим мужьям или партнёрам. Основываясь на убеждении, что женщины слишком слабы и беззащитны, не способны постоять за себя под давлением радикального феминизма роль защитника жертв взяло на себя государство в лице полицейских, судей, врачей, социальных работников.

Представители либерального направления критиковали радикальный феминизм за преувеличение агрессивности мужчин, отрицание и определение женской агрессии. Либеральный феминизм призывает к изучению женской агрессии, возможность испытывать негативные эмоции: злость, ярость, способность совершать насилие, но при этом также нести равную (с мужчинами) ответственность за свои действия. В большинстве западных исследований домашнего насилия и насилия против женщин радикальная феминистская теория, несомненно, доминирует [18].

Однако в последнее время всё чаще появляются исследования по изучению насилия, совершаемого женщинами. В диссертационном исследовании «Женское супружеское насилие» Е.А. Брайцева описала специфические формы женского насилия, такие, например, как единоличное решение об аборте, ограничение сексуальных контактов, упрёки в низких заработках мужа [2].

Основные положения радикальной феминистской теории.

1. Патриархат или гендерное неравенство в пользу мужчин и распределение власти в экономической, политической и социальной сферах общества также характерны для области семейных отношений. Патриархат ограничен почти в трети современных развитых обществ, включая Россию и Украину. Россия и страны СНГ унаследовали от советского режима систему, крайне деструктивную, в первую очередь для мужчин, а не для женщин. Индикатором таких различий служит разница в ожидаемой продолжительности жизни между мужчинами и женщинами в России, которая на протяжении последних двух десятилетий составляет 13 лет (60 лет среди мужчин и 73 года среди женщин) [6, с. 113].

Продолжительность жизни граждан Украины с 1991 г. по настоящее время сократилось на 15 лет. Согласно статистике ВОЗ, по показателю средней продолжительности жизни Украина отстала от стран Центральной Европы на 5,5 лет, а от стран ЕC - почти на 12 лет [8, с. 2].
2. Насилие в семье совершается в основном мужчинами против женщин. Более 200 исследований в США и других развитых странах, включая Россию и Украину, демонстрируют примерно одинаковый уровень насилия, совершаемого женщинами и мужчинами [19]. Штраус считает, что для измерения насилия нужно осторожно использовать инструмент для измерения насилия [20]. М. Джонсон отстаивает позицию, что существует как минимум три типа насилия: интимный терроризм, физическое сопротивление и ситуационное насилие в паре [18].

3. Если женщины совершают насилие в семье или в интимных отношениях против мужчин, то почти исключительно в целях самообороны. Исследователи США выявили крайние формы женской агрессии, в результате которой мужчины были вынуждены обратиться за помощью в полицию, но это скорее исключение, чем правило.

4. Социологи сделали вывод, что мужчины почти никогда не становятся жертвами внутрисемейного насилия.

Сексуальное насилие - одно из самых распространённых и серьёзных преступлений против личности. Сексуальное наслаждение предполагает свободу и добровольность, однако во всех человеческих обществах во все времена существовали различные сексуальные насилия. Это случается гораздо чаще, чем фиксирует официальная статистика, так как большинство жертв предпочитает молчать о случившемся. Сексуальная агрессия, крайним случаемкоторойявляетсяизнасилование, проявляется в трёх основных формах: сексуального домогательства, принуждения и насилия.

Сексуальное домогательство - навязчивое приставание в форме физического контакта или словесных замечаний и предложений, вопреки выраженному нежеланию лица. Не всегда можно отличить нежелательное сексуальное домогательство от настойчивого ухаживания. Мужская сексуальность зачастую содержит элементы агрессивности, что соответствует стереотипам поведения: мужчина должен «завоевать» женщину, сопротивление женщины его возбуждает.

Сексуальное принуждение, когда человек добивается сексуальной близости с другим вопреки его воле, но не прибегая к насилию. В неблагополучных семьях, а также в тех семьях, которые находятся на грани развода, сексуальное принуждение нередкое явление.

Особенно сложная социально-правовая проблема - защита детей и несовершеннолетних от сексуального насилия. Объясняется это тремя причинами: 1) дети зависят от взрослых; 2) они часто не осознают, что с ними делают, их «добровольность» может быть фиктивной; 3) обществу не безразличны 
долгосрочные последствия ранних сексуальных контактов. Поэтому если взрослых закон охраняет только от сексуального принуждения и насилия, то детей он защищает от любых покушений сексуального характера.

Никакой закон сам по себе не может защитить детей и подростков от сексуальных посягательств и злоупотреблений. В этой области бытует много ложных представлений.

Во-первых, в обществе распространено мнение, что сексуальные покушения на детей редки и являются признаком морального распада и деградации общества. На самом деле они были всегда. Так, по американским данным, каждаячетвёртая илипятаядевочка и каждый седьмой или девятый мальчик моложе 18 лет подвергался каким-либо сексуальным покушениям. Чаще всего пристают к подросткам, но четверть подобных случаев приходится на долю детей младше семи лет [5, с. 220].

Во-вторых, многие считают, что большинство сексуальных покушений совершают посторонние люди. На самом деле в четырёх случаях из пяти это делают те, кого ребёнок знает, чаще всего - кто-то из старших членов его собственной семьи. Из 927 американских студентов, опрошенных в начале 1980-х гг., сексуальные контакты с близкими родственниками имели в детстве $21 \%$ мужчин и 20,9\% женщин. Чаще всего «совратителями» бывают братья и сёстры (45\% девочек и 68\% мальчиков). На втором месте (38\% девочек и 10\% мальчиков) - отцы и отчимы. 6\% мальчиков имели сексуальные контакты с матерями [5, с. 220].

В-третьих, бытует мнение, что все взрослые, развращающие детей, психически больные или ненормальные люди. На самом деле педофилы, то есть люди, которых неодолимо влечёт именно к детям, составляют среди них незначительное меньшинство. Большинство же составляют самые обычные мужчины, среди которых много женатых и имеющих собственных детей.

В-четвёртых, сексуальные покушения на детейсовершаютсяглавнымобразомвбедной, необразованной среде и неполных семьях. Это мнение ложно, потому что сексуальные покушения на детей случается во всех слоях общества, с любым уровнем образования и дохода, во всех этнических и религиозных группах.

В-пятых, рассказывая о сексуальных покушениях, дети часто выдают воображаемое действие за действительное, по своей сути они лгут. На самом деле детские рассказы сложный сплав реальности и воображения, но пренебрегать ими так же неразумно, как и принимать их на веру.

В-шестых, многие считают, что дети и подростки - невинные жертвы и пассивные объекты сексуальных извращений взрослыми.
На самом деле рано развивающиеся дети сами провоцируют и даже поощряют взрослых к сексуальным контактам. Иногда это делается бессознательно, а иногда, особенно подростками, вполне осознано. Так что слово «совращение» не всегда правильно описывает характер таких взаимоотношений.

Субъективные реакции детей на сексуальное совращение неоднозначны. Среди американских студентов, переживших такую ситуацию, 52\% восприняли её отрицательно, $18 \%$ - нейтрально, а 30\% - положительно [5, с. 220].

Особенно сложной моральной и психологической проблемой является инцест, когда ребёнка совращают близкие родственники. Сексуальные отношения между братьями и сёстрами встречаются гораздо чаще, чем между родителями и детьми.

Единой теории инцеста не существует. Так, Зигмунд Фрейд считает, что инцест - универсальное свойство человеческой психики. Бронислав Малиновский объясняет запрещение инцеста необходимостью поддержания стабильности социальной структуры и семейных отношений, потому что сексуальные связи между членами семьи создают между ними опасную напряжённость. Робин Фокс связывает кровородственные связи с ухудшением генофонда соответствующей человеческой группы.

В настоящее время точной статистики инцеста не существует, потому что эти случаи держатся в глубоком секрете, как величайшая семейная тайна. Из ста случаев инцеста, описанных в одном американском исследовании, полиция знала только об одном [5, с. 221].

К сожалению, в Украине мало внимания обращается на социологические исследования по изучению случаев сексуального насилия, принуждения, домогательства, педофилии, сексуальной эксплуатации детей и подростков, а также инцест.

$\mathrm{K}$ негативным явлениям можно отнести и сожительство, когда пары живут вместе, вступая в половые отношения, но не состоят при этом в законном браке. Институт брака на современном этапе характеризуется двумя процессами: сохранением традиций, норм, сформированных в предыдущем периоде развития общества и формированием новообразований, которые обусловлены современными социальными явлениями. Ослабление традиционных норм - одна из причин сожительства, что является отражением институционального кризиса, который охватил все стороны социальных отношений, в том числе и семейных. Чертой этих отношений является аномия (слабость, неопределенность). Сожительство широко распространено в западных странах. В Швеции, Дании, Норвегии, Фин- 
ляндии, Германии сожительство стало нормой и рассматривается как «пробный» брак для пары, которая в будущем вступает в брак. В Швеции $50 \%$ детей рождается вне брака. Но даже в Швеции 75\% женщин, живущих с партнёрами старше 30 лет, официально зарегистрировали брак [13, с. 210].

Однако сожительство не является альтернативой браку. Сожительство, также как и однополые браки, является девиацией брачных отношений. Девиация (от лат. deviation уклонение) - отклонение от правильной линии [11, c. 148].

Сожительство или гражданский брак, кроме положительной черты, -возможности до вступления в законный брак больше узнать о своём партнёре, к сожалению, имеет целый ряд недостатков, а именно:

- подрывает готовность партнёров выполнять свои социальные семейные роли;

- не обеспечивает функционирование семьи как социального института;

- это угроза семье как фундаменту общества;

- ослабляется репродуктивная функция общества;

- слабая инициатива для побуждения индивида к интернализации нормативных ожиданий по поводу принятых в обществе форм брака;

- неудовлетворительное использование разных методов организации социального опыта молодых людей по отношению к принятым в обществе формам брака;

- неэффективные разные формальные и неформальные санкции к носителям брачных девиаций [15].

Социологический опрос среди молодых мужчин и женщин Украины, проведенный в 2007 г., показал, что позитивно относятся к гражданскому браку 44\% респондентов, что в два раза больше тех, кто относится к гражданскому браку отрицательно (18,6\%). И хотя за последние годы в украинском обществе изменилось мнение о сожительстве, однако в целом менее 50\% молодёжи одобряют гражданский брак [16, с. 226].

Дети, рождённые в сожительстве, не являются законными. Хотя в некоторых странах, включая Великобританию, закон признаёт, что люди, живущие вместе, но не заключившие брак, имеют те же права, что и брачная пара [3, с. 143].

В 1994 г. в Англии было проведено интервью с 5000 домохозяйств, которое показало, что более половины всех 25-летних сожительствовали с партнёрами, тогда как 25 годами ранее сожительство фиксировалось в количестве 1-2\%. Рост числа сожительствующих пар и рождения детей вне брака изучались в Англии Кэтлин Киран и Валери Эсто.
Они установили:

1) сожительствующие пары обычно молоды - семь из 10 пар моложе 35 лет;

2) из трёх пар в двух партнёры никогда не состояли в браке;

3) к 1989 г. $26 \%$ одиноких людей сожительствовали, по сравнению с 3\% в 1979 г.;

4) к 1991 г. количество рождений вне брака составляло $30 \%$;

5) пары обычно сожительствуют недолго. Каждая третья пара была вместе меньше одного года, в то время как 16\% были вместе более 5 лет [13, с. 209].

Сожительство приводит к тому, что мужчины чаще всего считают себя холостыми, а женщины чувствуют себя замужними. Женщины больше стремятся сохранить свой гражданский брак, тогда как мужчины при сожительстве стараются не брать на себя каких-либо обязательств не только по отношению к своей избраннице, но и прежде всего по отношению к детям. В случае развода нужно через суд восстанавливать права и жене, ранее состоявшей в незарегистрированном браке, и родившимся от сожительства детям.

Индустриализация стран, в том числе и Украины, вовлечение женщин в производительный труд вне дома накладывает отпечаток на воспитание подрастающего поколения.

По данным социологических исследований, в Украине, России, Белоруссии и других странах СНГ в среднем работающая женщина в сутки уделяет воспитанию детей 16 минут, в выходные дни - 30 минут [12, с. 467].

Основные причины плохого воспитания детей:

- низкий экономический уровень развития Украины, когда основная масса времени родителей тратится на добывание средств для существования (заработной платы для приобретения продуктов питания, промышленных товаров и так далее);

- низкая культура общественной жизни, куда редко вовлекаются родители совместно с детьми;

- демагогичность общества, связанная с двойной моралью [12, с. 467].

Трудовая нагрузка женщины-горожанки в простых семьях с детьми составляет 77 часов в неделю, в том числе дома 36 часов, то есть среднийрабочийденьженщины-матери, включая воскресенье, длится 11 часов [3, с. 467].

Неравенство женщин и мужчин в браке основная причина распада молодых семей. Неумение и нежелание, прежде всего, мужчин помогать жене в ведении домашнего хозяйства и воспитании детей приводит к серьёзным конфликтам между супругами и отрицательно сказывается на воспитании детей.

Имеется школьный курс «Этика и психология семейной жизни». Но читался он очень 
короткое время, а потом его растворили в общем курсе «Человек и общество». Нет специалистов для его преподавания. Разговор ведётся на уровне «детского сада». По данным социологических исследований, проведенных в Киевских школах, 90\% школьников считают, что курс «Этика и психология семейной жизни» обязательно следует читать в школе. Эти же исследования показали, что о специфических отношениях между мужчиной и женщиной узнали в 9-10 лет и раньше 42\% опрошенных, в 10-12 лет - 24\%, в 13-14 лет 33\%. Отсюда вывод, когда изучаются отношения между мужчиной и женщиной, то все уже «образованы». Кем же? Для 50\% «просветителями» стали сверстники, 30\% - специальная и популярная литература, 24\% - старшие ребята. Только 3\% школьников назвали своих родителей в качестве тех, кто им объяснил тактично сложные вопросы физиологического рождения человека. Никто из опрошенных не назвал учителей, призванных дать научные знания по всем сферам жизни людей. Также социологические исследования показали, что 40\% девочек интересуются вопросами организации семейной жизни, 33\% хотят знать проблемы, возникающие в семье при воспитании детей. Напряжённая, конфликтная обстановка во многих семьях приводит к тому, что 45\% подростков никогда не говорят дома о том, что они узнали в школе об этике и психологии в семейной жизни. Делятся с матерями мыслями и чувствами, возникшими на уроке, около 30\% девочек и только 6\% указали, что беседуют с отцами [12, с. 468].

В настоящее время вместо курса «Этика и психология семейной жизни» в средних школах Украины вводится новый курс «Семейные ценности». Департамент образования и науки города Запорожья, кафедра социологии и социальной работы Классического приватного университета провели социологическое исследование «Эффективность внедрения семейно-родственного воспитания в образовательной системе г. Запорожье». Возглавил проведение социологического исследования кандидат социологических наук, доцент кафедры социологии и социальной работы КПУ Ф.С. Хрусталёв.

В результате социологического исследования было опрошено 703 ученика 8-10 классов 13 средних школ г. Запорожья. Были охвачены исследованием все районы города. Из опрошенныхучеников восьмыхклассов было 35,8\%, девятых - 33,4\%, десятых - 30,8\%. Среди них девочек было 57,7\% и подростков мальчиков 42,3\%. Возраст респондентов: 13 лет - 22,7\%, 14 лет - 32,4\%, 15 лет - 30,2\%, 16 лет - 14,7\%. Метод сбора информации: анкетирование. Максимальное отклонение результатов, полученных с помощью выборочного анкетиро- вания от данных генеральной совокупности, составило 3,1\%. Время проведения социологического исследования декабрь 2016 г. Среди учеников средних учебных заведений г. Запорожья в первую тройку наиважнейших ценностей входят: семья - 98,2\%, образование - 96,7\% и самореализация - 95,9\%. Наличие друзей стоит на четвёртом месте 95,3\%. Установлена разница в ранжировании ценностей среди учеников школ, в которых был осуществлён курс семейно-родственного воспитания, и в тех, где его не было. Наглядно есть разница в отношении к семье: хотя она и занимает первую позицию, но ценности её меньше среди учеников, которые не изучали курс «Семейные ценности» [17].

Большую проблему для украинского общества представляют беспризорники, или как их еще называют «дети улицы». Согласно данным ЮНИСЕФ - Детского фонда ООН, количество беспризорников в возрасте от 10 до 19 лет в Украине составляет около 150-160 тысяч человек [14, с. 3].

Социологи и педагоги отмечают основные социально-экономические причины возникновения беспризорности: войны, голод, стихийные бедствия и другие изменения условий жизни, влекущие за собой сиротство детей. Во вторую очередь они называют следующие причины возникновения беспризорности: экономические кризисы, безработицу, нужду, детскую эксплуатацию, ослабление семейных устоев, морально-психологический кризис, распространение психических заболеваний, конфликтную обстановку в семьях, асоциальное поведение родителей и жестокое обращение с детьми.

Беспризорность была и в первые годы советской власти. Наивысших своих отметок она достигла в 1922 г., когда беспризорных детей насчитывалось, по разным данным, от 5 до 7 миллионов. А уже через три года, в условиях хозяйственной разрухи, голода, эпидемий число зарегистрированных беспризорников сократилось до трети миллиона. Решение проблемы беспризорности было объявлено не социальной, а политической задачей. Уже в 1919 г были образованы: Государственный совет защиты детей во главе с А.В. Луначарским, в 1921 г. - Комиссия по улучшению жизни детей «Деткомиссия ВЦИК» во главе с Ф.Э. Дзержинским, Народный комиссариат просвещения, социальные инспекции на местах для оказания помощи беспризорным детям [10, с. 3].

Правительство заботилось о получении воспитанниками интернатов общего политехнического образования и усвоения практических производственных навыков, чтобы подготовить их к общественно-трудовой деятельности. С этой целью при детских домах 
были организованы тысячи мастерских, узаконена бронь на производстве для подростков из детдомов.

K сожалению, опыт советского правительства не явился примером для Украины в вопросе работы с «детьми улицы», хотя общие черты поведения беспризорников сохраняются и до настоящего времени. У беспризорников сильно развит инстинкт самосохранения, они отличаются повышенной возбудимостью, склонностью к наркотикам и алкоголю, многие из них преждевременно начинают половую жизнь. Они активны, выносливы, подчинены логике коллективных действий, у них стирается понимание ценности человеческой жизни, они отвергают законы любой морали, кроме той, которая действует в их локальной группе. Это приводит ктому, что безнадзорные дети пополняют криминальные сообщества и даже становятся их организаторами - беспощадными, чуждыми к состраданию. Таким образом, они несут угрозу не только своим сверстникам, но и взрослым, что выливается во всё растущее количество преступлений, совершаемых подростками.

Отсутствие правильного трудового воспитания беспризорников опасно тем, что «дети улицы» - это потерянное для общества поколение, потому что им не привиты навыки труда, они привыкли ничего не делать, не учиться, они ничем, кроме хлеба насущного, не интересуются. Такие дети, даже став взрослыми, уже никогда не станут к станкам на производстве, не пополнят страну произведениями искусства и вообще не станут полноценными людьми. Они, воспитанные вне семьи, не создадут настоящие семьи, не будут стремиться к рождению детей, что пагубно отразится на демографической ситуации в стране.

Нельзя умолчать и о таком пагубном факте в стране, как наличие лиц без определённого места жительства (БОМЖей). Официальная статистика насчитывает их 30 тысяч человек, а неофициальная - 130 тысяч. К ним относятся и 30\% тех, кто покинул места лишения свободы, но юридически нигде не числится, что составляет увеличение численности бомжей около 25 тысяч в год [9, с. 1].

Точную цифру количества бездомных в любой стране получить крайне сложно. Однако если на 309,5 миллионов граждан самой богатой страны мира США приходится 3,5 миллиона бездомных; на одну из самых богатых стран Европы - Францию (с довольно высокими социальными стандартами) на 65 миллионов человек населения приходится 100 тысяч человек бездомных, то Украина с населением в 42 миллионов человек вполне вписывается в стандартные рамки бездомности, которые являются неотъемлемым элементом рыночных капиталистических отношений [7, с. 73].
Среди беспризорников и БОМЖей много лиц, употребляющих наркотики, имеющих психические заболевания и даже тех, кто заражен ВИЧ/СПИДом.

Наркоманов в Украине становится всё больше и не только среди беспризорников или БОМЖей. Сегодня в каждой десятой украинской семье живёт наркоман. Таковы результаты исследований «Наркомания в Украине», проведенных с 9 по 11 августа 2010 г. сотрудниками Института имени Горшенина. Респонденты были из всех областей Украины. 73,5\% из них считают, что меры, которые принимают правоохранительные органы для борьбы с наркоманией, недостаточны.

Минздрав сообщает, что в Украине наркозависимых свыше 200 тысяч. А независимые эксперты считают, что их намного больше. Ежегодно в Украине количество наркоманов увеличивается на 8\%. Ныне коэффициент наркоматизации населения страны лишь по официальным данным достигает $2 \%$. Украина вошла в первую десятку стран по темпам поражения наркоманией. С начала 90-х годов ряды наркозависимой молодёжи ежегодно пополняются. Из них взрослых - 27\%, подростков - 60\%, 11-14 -летних детей - 13\% [14, с. 3].

В Украине быстро растёт число ВИЧинфицированных женщин. Наша страна имеет самую острую эпидемиологическую ситуацию с ВИЧ/СПИДом в Европе и среди стран СНГ [14, с. 2].

Выводы из проведенного исследования. Социологи всего мира обеспокоены ростом негативных явлений в семейно-брачных отношениях, таких как: рост насилия в семье; сексуальные домогательства и принуждения; зарегистрированные инцесты; увеличение количества однополых (гомосексуальных) семей; рост сожительства; ухудшение воспитания детей в семьях (особенно в тех, где работают женщины); наличие беспризорников и БОМЖей; широкое распространение наркотиков и заболеваний ВИЧ/ СПИДом.

Bce эти негативные явления присущи и современной украинской семье. Как показывают современные социологические исследования, насилию в семье подвергаются не только женщины (жёны), но и мужчины и другие члены семьи. Борьба с насилием в семье является одной из насущных проблем семейно-брачных отношений. Нельзя допускать насилие против любого члена семьи и прежде всего насилие по отношению к детям, посколькуони самые бесправныечлены семьи.

Не может остаться в стороне и проблема гомосексуальных семей. Стремление Украины в Европу, овладение европейскими ценностями сталкивается с признанием в правовом поле однополых семей. Это встречает сопро- 
тивление и непринятие таких брачных союзов со стороны большинства населения Украины.

Большой проблемой для Украины является широкое распространение наркотиков, а также наличие в обществе огромного количества беспризорных детей и БОМЖей. Статистика показывает, что «детей улицы» насчитывается порядка 150-160 тысяч человек, а БОМЖей - по неофициальной статистике 130 тысяч. Борьба с уменьшением количества «детей-улицы» и БОМЖей является серьёзной проблемой для всей Украины.

Украина в последние годы вышла на первое место в Европе по скорости распространения СПИДа. Это тоже большая проблема, потому что если скорость распространения такой тяжёлой болезни сохранится в ближайшие годы на том же уровне, то Украина рискует выйти на первые места по количеству лиц, которые заболели СПИДом.

\section{ЛИТЕРАТУРА:}

1. Большой толковый социологический словарь (Collins) / Дэвид Джери, Джулия Джери. В 2-х томах. Пер. с англ. Москва, Вече, АСТ, 1999. Том 1. 544 с. ; T. 2.528 c.

2. Брайцева Е.А. Женское супружеское насилие : автореф. дисс. ... канд. соц. наук. Нижний Новгород, 2008.

3. Гиденс Э. Социология. Пер. с англ. Москва, 1999.

4. Гоцуенко Н. Такая супружеская чета: муж - неженатый, жена - замужем. Газета «Зеркало недели» №44 (469) 15 ноября 2003 г.

5. Кон И.С. Введение в сексологию: учебное пособие. Москва : Олимп ИНФРА - М., 1999. 288 с.

6. Лысова А.В. О границах радикальной фреминистской теории и объяснение насилия в семье. Право Украины. № 4, 2012, с. 110-117.

7. Малахова Ж.Д. Пути преодоления бедности в современной Украине. Гуманітарний вісник Запорізької державної інженерної академії: збірник наукових праць № 50 / Гол. ред.. В.Г. Воронкова. Запоріжжя ЗДІА, 2012. С. 71-81.
8. Мороз Л. Скрытый голодомор. Газета «Коммунист», 12 июля 2010 г.

9. Нормы капитализации: бездомный. Газета «Коммунист». № 13 (1471), среда, 15 фревраля, 2012 г.

10. Симоненко Р. Они ничьи... Те, которые н икому не нужны. Газета «Киевский вестник». 14 августа 2012 г.

11. Словарь иностранных слов. 13 изд., стереотип. Москва, Рус. яз. Москва, 1986. 608 с.

12. Социология. Наука об обществе : учебное пособие / Под общ. ред. проф. В.П. Андрущенко, проф. Н.И. Горлача. Харьков, Институт востоковедения и международных отношений. Харьковский коллегиум. Кафедра истории, филлософии и политических наук. 1996, с. 688.

13. Томпсон Л. Социология: вводный курс / Л. Томпсон, Д. Пристли. Социология: вводный курс / Пер. с англ. Москва : ООО «Фирма Издательство АСТ» ; Львов : «Инициатива»,1998. 496 с. (Классики зарубежной психологии).

14. Хлебникова Т. Это страшное слово «наркотик». Газета «Киевский вестник». Декабрь 2011 г.

15. Щербина В.В. Норми та девіації сучасного шлюбу : авторефр. дис. канд. соціологічних наук. Запоріжжя : КПУ, 2008.

16. Щербина В.В. Сопоставление мнений молодых мужчин и женщин о гражданском браке. Молодь в умовах нової соціальної перспективи: Матеріали IX Міжнародної науково-практичної конфреренції. Житомір, 2007. С. 225-227.

17. Felix Rhrustaliov. Ефективність фрорм впровадження сімейно-родинного виховання в освітній системі м. Запоріжжя. Результати соціологічного дослідження.

18. Yohnson M.P. Atypolocy of domestic violence: intimate terrorism, violent resistance, and situational couple violence. Boston : Northeastern Universitety Press, 2008.

19. Stark E. Coercive control: the entrapment of women in personal lipe. New Jork : Oxford Universitety Press. 2007.

20. Straus M.A. Thirty years of denying the evidence on gender symmetry in partner violence: implications tor prevention and treatment. Partner Abuse, 2010, № 1. 